\title{
WIP: Characterizing Conceptual Change about Moments in a Statics Course
}

\section{Dr. Chris Venters, East Carolina University}

Chris Venters is an Assistant Professor in the Department of Engineering at East Carolina University in Greenville, North Carolina, USA. He teaches introductory courses in engineering design and mechanics and upper-level courses in fluid mechanics. He earned his Ph.D. in Engineering Education from Virginia Tech in 2014, and his research primarily focuses on conceptual understanding in engineering mechanics courses. He received his M.S. in Aerospace Engineering from Virginia Tech and his B.S. in Aerospace Engineering from North Carolina State University.

Ms. Katie Brown, 


\section{WIP: Characterizing Conceptual Change about Moments in a Statics Course}

Statics is a critical course for engineering students. Although it builds on topics generally covered in high school or undergraduate-level physics, for many students it is their first formal instruction to engineering mechanics and thus lays the foundation for future study of engineering. Student conceptual understanding of statics content continues to be an area of concern for educators (e.g., [1]-[5]). Not surprisingly, common errors and conceptual difficulties for students in statics relate to forces and creating free-body diagrams [6]. Moments (of a force) have also been identified as a particular area of confusion for students both because of conflicting terminologies [3] and their role as "intermediate quantifier[s] of the rotational effect of interactions [between bodies]" [7]. That is, while the net force is the quantity proportional to a mass's translational acceleration, the moment is proportional to the mass's angular acceleration. That moments build on the already difficult concept of force likely only complicates learning. This work in progress paper describes an early pilot of a study to investigate the process of conceptual change related to moments in an engineering statics course. Preliminary results from the pilot provide insight into the structure of novice knowledge about moments and will help inform future data collection.

\section{Literature Review}

Conceptual change broadly studies how concepts are acquired and revised by learners. The exact processes by which this change occurs and what makes them difficult to execute is the subject of several theories for which Streveler et al. provide an overview in [8].

Most conceptual knowledge studies in engineering to date look for evidence of existing knowledge and/or misconceptions that students possess at a point in time, and in some cases, how these change over time as a result of instruction or other learning activities (e.g., [9]-[11]). Typically, these are situated in a course or discipline, though a few studies synthesize misconception characteristics that transcend courses and/or disciplines. Montfort et al. provides one such example in their attempt to move beyond classification and cataloging of specific student misconceptions to look for broader themes and commonalities in the ways that students experience conceptual difficulties across engineering disciplines [12]. They report two themes: that students tend to inappropriately group distinct, yet broadly-related discipline-specific terms, and that students tend toward simple causal narratives to reason about engineering phenomena that they know should be somehow related. Still, the mechanisms and processes through which conceptual change occurs in engineering are not often studied directly. As a result, the ways that students acquire and revise concepts are not well understood. Data collection for this study attempted to document with finer granularity the formation and revision of student conceptions relating to the topic of moments over time in a statics course. 


\section{Research Setting and Methods}

Data collection for this study took place at a large public university in the southeastern United States. At the institution, statics is offered to all engineering students through multiple facultyled sections of approximately 30 students. Participants were recruited through in-class visits during which the study was described and students were given the option of confidentially volunteering to be contacted via email to participate. In total, 10 students ultimately responded to the request to schedule an initial interview. Six participants completed the full series of 3 interviews over a span of two months at equally spaced intervals. The first interview took place approximately halfway through the semester, near the time when moments were first introduced in the course. The second interview took place after students had been tested on rigid body equilibrium and structures, and the final interview took place during the institution's final exam period at the end of the term. All interviews were audio-recorded for later transcription. The interview protocol included several questions attempting to probe the participants' conceptions of moments and was semi-structured to allow for further exploration of responses when possible.

The complete interviews will be analyzed in a future study. For the current study, we focus on three questions that were asked during each of the three interviews:

1. What is your current understanding of the term "moment"?

2. What causes moments?

3. What is the relationship, if any, between moments and rotations?

The answers to these questions were selectively transcribed and, for each participant, the responses across the three interviews were compared. Next, potential themes across participants were explored.

\section{Preliminary Findings}

Transcription and analysis of the complete set of interview questions is ongoing, but we highlight some preliminary findings from the three questions presented above.

The responses to question 1 vary between participants, though most gave explanations that seem consistent across their three interviews. Three of the participants initially offered descriptions of moments that included reference to rotations, even before question 3 was presented and even when given in conjunction with typical colloquial descriptions like "force at a distance". They describe moments as "like a rotation" or "pretty much a rotation". For some, these thoughts seemed to persist and solidify over time. In the final interview, Branden states simply, "I think it's a rotation about a point. So, force applied at a distance." One participant, Jacob, mentions some difficulty in the first interview distinguishing between moments and actual realized motion, yet by the final interview, this explanation is replaced by "a combination of a force and that force is separated by a distance" with no mention of motion. Jasmine, who recalled a textbook 
definition of moment as being "a tendency to rotate" in her first interview, provided similar explanations in later interviews.

All six participants identified that forces were responsible for moments in response to question 2. This remains consistent across interviews.

For the participants who brought up rotations in question 1, the responses to question 3 followed similarly. These participants reported that moments and rotations are "the same", "equal", or at the least have a direct causal relationship. Jasmine explains that rotations are caused by moments "if there's nothing to stop [the object]" in her first interview, but struggles during the second and third interviews when trying to parse moments and rotations in more detail.

\section{Discussion of Results and Limitations}

Many participants' initial notions of moments persisted throughout the term. This may indicate that change did not occur over the period studied or is not identifiable from the responses elicited by the questions. All participants stating forces as the cause of moments is positive though not surprising given that forces routinely appear in the free-body diagrams and mathematical equations that students gain familiarity with during the course.

The misconception reported by three of the six participants that moments and rotations are the same is interesting and should be explored further. This conflation of moments and rotations might reflect "inappropriate groupings" or overly simple causal narratives created by students like those described in [12]. Even Jasmine, who provided the correct definition of moment consistently, struggled with its relationship to rotation. Further analysis of the full interviews may help provide clarification of the type of misconception as well as factors that influence its development or reinforcement. For example, Kayla mentions that the terms are "usually in the same sentence" when discussed in class, leading her to see them as the same. Thus, the misconception might be reinforced by analogies typically used in instruction. The effects of this misconception on course performance might also be explored.

Aside from being incomplete, we acknowledge some further limitations to the current work presented. First, interviews were conducted after moments had already been presented in class for most participants. Having the first interview earlier in the term would help determine what prior knowledge students have with the term moment, if any. Second, participation in the interviews may be a source of conceptual change that non-participating students would not encounter in a classroom setting. This was not evident from the results presented here, however, and our goal is to investigate the process of change regardless of source. It is hoped that further analysis and future findings can help better characterize the structure of novice knowledge about moments and the processes by which it develops within an engineering context. 


\section{References}

[1] P. S. Steif and J. A. Dantzler, "A Statics Concept Inventory: Development and Psychometric Analysis," Journal of Engineering Education, vol. 94, (4), pp. 363-371, 2005.

[2] P. S. Steif et al, "Improving Problem Solving Performance by Inducing Talk about Salient Problem Features," Journal of Engineering Education, vol. 99, (2), pp. 135-142, 2010.

[3] L. Passmore et al, "Sources of students' difficulties with couples and moments in statics," in ASEE Annual Conference and Exposition, Louisville, KY, 2010.

[4] C. Venters et al, "Using Writing Assignments to Improve Learning in Statics: A Mixed Methods Study," International Journal of Engineering Education, vol. 34, (1), pp. 119-131, 2018.

[5] O. Ha, S. Brown and N. Pitterson, "An Exploratory Factor Analysis of Statics Concept Inventory Data From Practicing Civil Engineers," International Journal of Engineering Education, vol. 33, (1), pp. 236-246, 2017.

[6] P. S. Steif, "An articulation of the concepts and skills which underlie engineering statics," in 34th Annual Frontiers in Education, 2004. FIE 2004. 2004, pp. F1F-5-10 Vol. 2.

[7] R. A. Streveler et al, "Learning Conceptual Knowledge in the Engineering Sciences: Overview and Future Research Directions," Journal of Engineering Education, vol. 97, (3), pp. 279-294, 2008.

[8] R. Streveler et al, "Conceptual change and misconceptions in engineering education: Curriculum, measurement, and theory-focused approaches," in Cambridge Handbook of Engineering Education Research, 1st ed., A. Johri and B. Olds, Eds. Cambridge University Press, 2014, pp. 83-101.

[9] C. Venters, L. McNair and M. Paretti, "Using writing assignments to improve conceptual understanding in statics: Results from a pilot study," in ASEE 112th Annual Conference and Exposition, San Antonio, TX, 2012.

[10] D. Montfort, S. Brown and D. Pollock, "An Investigation of Students' Conceptual Understanding in Related Sophomore to Graduate-Level Engineering and Mechanics Courses," Journal of Engineering Education, vol. 98, (2), pp. 111-129, 2009.

[11] R. Taraban et al, "First Steps in Understanding Engineering Students' Growth of Conceptual and Procedural Knowledge in an Interactive Learning Context," Journal of Engineering Education, vol. 96, (1), pp. 57-68, 2007.

[12] D. Montfort et al, "Patterns of Student Conceptual Understanding across Engineering Content Areas," International Journal of Engineering Education, vol. 31, (6), pp. 1587-1604, 2015. 